\title{
Association between Lower Normal Free Thyroxine Concentrations and Obesity Phenotype in Healthy Euthyroid Subjects
}

\author{
Jeong Ah Shin, ${ }^{1}$ Eun young Mo, ${ }^{1,2}$ Eun Sook Kim, ${ }^{1,2}$ Sung Dae Moon, ${ }^{1,2}$ and Je Ho Han ${ }^{1,2}$ \\ ${ }^{1}$ Division of Endocrinology and Metabolism, Department of Internal Medicine, College of Medicine, \\ The Catholic University of Korea, 222 Banpo-daero, Seocho-gu, Seoul 137-701, Republic of Korea \\ ${ }^{2}$ The Catholic University of Korea Incheon St. Mary's Hospital, 665 Bupyung-6-dong, Bupyung-gu, \\ Incheon 403-720, Republic of Korea \\ Correspondence should be addressed to Eun Sook Kim; 13900@catholic.ac.kr
}

Received 30 January 2014; Revised 29 March 2014; Accepted 29 March 2014; Published 28 April 2014

Academic Editor: Amelie Bonnefond

Copyright (C) 2014 Jeong Ah Shin et al. This is an open access article distributed under the Creative Commons Attribution License, which permits unrestricted use, distribution, and reproduction in any medium, provided the original work is properly cited.

\begin{abstract}
We investigated whether thyroid function could identify obesity phenotype in euthyroid subjects. A cross-sectional analysis was performed among nondiabetic, euthyroid subjects. We stratified subjects into four groups by BMI and insulin resistance (IR). Of 6241 subjects, $33.8 \%$ were overweight or obese (OW/OB) and $66.2 \%$ were normal weight (NW). Free thyroxine (FT4) levels were negatively associated with body mass index, waist circumference, triglyceride, c-reactive protein, and HOMA-IR and positively with high-density lipoprotein cholesterol in both genders. In multivariate regression analysis, FT4 level, a continuous measurement, was negatively correlated with HOMA-IR ( $\beta=-0.155, P<0.001$ in men; $\beta=-0.175, P<0.001$ in women). After adjustment for age, sex, metabolic, and life style factors, subjects in the lowest FT4 quartile had an odds ratio (OR) for IR of 1.99 (95\% confidence interval 1.61-2.46), as compared to those in the highest quartile. The association between low FT4 and IR remained significant in both NW and OW/OB subgroups. In conclusion, low normal FT4 levels were independently related to IR in NW and OW/OB euthyroid subjects. Further studies are needed to investigate the mechanisms by which low FT4 levels are linked to high IR in euthyroid ranges.
\end{abstract}

\section{Introduction}

Obesity is closely associated with increased risk of cardiovascular disease (CVD) and is related to insulin resistance and its associated abnormalities such as hyperglycemia, hyperlipidemia, and hypertension [1]. However, obesity is not necessarily synonymous with insulin resistance, despite their strong correlation [2]. Current data describe that obese (OB) and normal weight (NM) subjects could be divided into "metabolically healthy" and "metabolically unhealthy" subsets according to insulin resistance or its related factors, suggesting that these distinctions are better predictors for the development of CVD and increased mortality than obesity itself [3]. However, related factors and underlying mechanisms for these paradoxical associations between obesity and insulin sensitivity or NW and insulin resistance have not been clarified.
Thyroid hormone regulates basal energy expenditure and influences the glucose and lipid metabolism [4]. Epidemiological studies have demonstrated increased CV events and mortality in subjects with subclinical as well as overt hypothyroidism, proposing substantial impact of thyroid insufficiency on atherosclerotic vascular changes in a graded manner [5]. This is further supported by close associations between thyroid insufficiency and clusters of metabolic abnormalities such as obesity and lipid profiles, observed even within physiological ranges [6-10], suggesting insulin resistance as a potential mechanistic link to the promotion of atherosclerosis. However, a limited number of data exist on the association between thyroid function and insulin activity in euthyroid subjects, especially when considering the influence of obesity.

Therefore, in this study we explored the relationship between thyroid function measured by FT4 and TSH levels 
and obesity and insulin resistance in healthy euthyroid subjects. Further, we investigated whether thyroid function could be an indicator of an insulin resistant phenotype in $\mathrm{OB}$ and normal NW subjects.

\section{Methods}

2.1. Study Population. A cross-sectional analysis was conducted among healthy, nondiabetic Koreans who underwent a general health check-up at Seoul St. Mary's Hospital Health Promotion Center between March 2009 and December 2010. A total of 8701 subjects between the ages of 20 and 80 years with data on a thyroid function and fasting plasma insulin (FPI) concentrations were considered for the present study. Exclusion criteria were: (i) TSH values out of the normal range, (ii) use of antithyroid drugs or thyroid hormone medication, (iii) a history of diabetes (or fasting serum glucose $\geq 126 \mathrm{mg} / \mathrm{dL}$ ), cardiovascular, cerebrovascular, or peripheral vascular disease, (iv) serum creatinine levels $\geq 1.5 \mathrm{mg} / \mathrm{dL}$, (v) body mass index $(\mathrm{BMI})<18.5 \mathrm{~kg} / \mathrm{m}^{2}$ : 6241 subjects were included in the final analysis. This study was approved by the institutional review board of Catholic University College of Medicine, Seoul, Korea. The informed consent was not required due to the retrospective nature of our study.

2.2. Measurement of Anthropometric and Biochemical Parameters. Medical history and social-behavioral information were collected through questionnaires completed by patients. Physical examinations were performed by measuring height, weight, waist circumference (WC), and blood pressure (BP) according to standardized methods. During measurements, the subjects were barefoot and wearing light clothing. BMI was calculated by dividing weight by the height squared $\left(\mathrm{kg} / \mathrm{m}^{2}\right)$. Before the measurement of BP, the subjects were resting in a sitting position for 10 minutes. BP was measured twice with at least a 5 min interval to obtain an average value. Blood samples were collected after the subjects had fasted at least 10 hours. The fasting plasma glucose (FPG), hemoglobin Alc (HbAlc), total cholesterol (TC), triglyceride (TG), highdensity lipoprotein cholesterol (HDL-C), and low-density lipoprotein cholesterol (LDL-C) were determined enzymatically using the Hitachi 7600 chemistry analyzer (Hitachi, Tokyo, Japan). The serum CRP level was measured with a turbidimetric immunoassay (Wako Chemicals $\mathrm{GmbH}$, Neuss, Germany). Fasting insulin levels were measured using commercially available RIA kits (Insulin RIA beads, TFBJapan Co. Ltd., Japan). The serum FT4 and TSH levels were measured by enzyme immunoassay using a commercially available kit (ADVIA Centaur, Seimens, Germany). The reference ranges of FT4 and TSH were $0.93-1.70 \mathrm{ng} / \mathrm{dL}$ and 0.35-5.50 mU/L, respectively.

2.3. Definition of Metabolic Abnormalities and Insulin Resistance. Subjects were classified as being normal weight (NW: BMI, 18.5-24.9 kg/m²), overweight (OW: BMI, 25.0$29.9 \mathrm{~kg} / \mathrm{m}^{2}$ ), or obese (OB; BMI, $\left.\geq 30.0 \mathrm{~kg} / \mathrm{m}^{2}\right)$. Hypertension was defined as systolic blood pressure (SBP) $\geq 140 \mathrm{~mm} \mathrm{Hg}$ or diastolic blood pressure (DBP) $\geq 90 \mathrm{~mm} \mathrm{Hg}$ or the use of antihypertensive drugs whereas hyperlipidemia was defined as total cholesterol $\geq 240 \mathrm{mg} / \mathrm{dL}, \mathrm{TG} \geq 150 \mathrm{mg} / \mathrm{dL}$ or the use of antihyperlipidemic drugs. The degree of insulin resistance assessed by homeostasis model assessment of insulin resistance (HOMA-IR) calculated as follows: HOMA-IR = fasting insulin $(\mu \mathrm{U} / \mathrm{mL}) \times$ FPG $(\mathrm{mmol} / \mathrm{L}) / 22.5$. Subjects were classified as being insulin resistant (top quartile of the HOMA-IR distribution) or insulin sensitive (lower 3 quartiles of HOMA-IR distribution).

2.4. Statistical Analysis. Statistical analyses were performed using SAS version 9.1 (SAS Institute, Cary, NC, USA). Data were expressed as mean \pm SD or number (percentage) unless otherwise stated. A one-way analysis of variance for continuous variables and the chi-square test for categorical variables were performed to compare characteristics of the study population. Pearson's correlation analyses were performed to examine the association between FT4 and TSH levels with various parameters. Due to skewed distribution, logtransformed FT4, TSH, TG, FPI, HOMA-IR, and CRP were used in the analysis including them as a continuous variable.

To determine the independent association between FT4 concentrations and insulin resistance as a continuous measure, multiple linear regression analysis was performed. FT4 quartiles were categorized separately as follows: Q1, < 1.22; Q2, 1.22-1.33; Q3, 1.34-1.48; and Q4, $\geq 1.49 \mathrm{mg} / \mathrm{dL}$ for men; Q1, < 1.13; Q2, 1.13-1.25; Q3, 1.26-1.40; and Q4, $\geq 1.41 \mathrm{mg} / \mathrm{dL}$ for women. The odds ratios (ORs) and 95\% confidence intervals (CI) for insulin resistance were assessed using multivariate logistic regression analyses according to quartile of FT4 levels. $P$ values of $<0.05$ were considered statistically significant.

\section{Results}

3.1. Characteristics of Subjects Categorized by Obesity and Insulin Resistance. Of 6241 subjects, $33.8 \%$ were OW/OB and $66.2 \%$ were NW. In the subgroup of the highest quartile of insulin resistance, 1145 were OW/OB-IR and 965 were NWIR (Table 1). Individuals in the OB/OW category were more likely to be male and to have unfavorable metabolic profiles such as higher BMI, WC, SBP, DBP, TC, TG, HDL-C, FPI, and HOMA-IR, whereas they were less likely to do regular exercise, as compared to those in the NW category. Similarly, individuals in the insulin-resistant groups had higher adiposity, SBP, DBP, TG, HDL-C, FPG, FPI, and HOMAIR and they showed lower FT4 and HDL-C, as compared to subjects in the insulin sensitive groups within the same BMI category. In contrast, subjects in the OW/OB-IS group showed similar levels of SBP, DBP, TG, and CRP compared with those in the NW-IR group, but lower levels of FPG, FPI, and HOMA-IR.

3.2. Associations between Anthropometric and Metabolic Parameters and Thyroid Hormone Concentrations, as Continuous and Categorized Forms. FT4 levels were negatively associated with cardiometabolic risk factors such as BMI, WC, 
TABLE 1: Clinical characteristics of the 6241 subjects.

\begin{tabular}{|c|c|c|c|c|c|}
\hline & NW-IS & NW-IR & OB/OW-IS & OB/OW-IR & $P$ \\
\hline$N$ & 3536 & 595 & 1145 & 965 & \\
\hline Male sex (\%) & $1649(46.6)$ & $279(46.9)$ & $809(70.7)$ & $667(69.1)$ & $<0.001$ \\
\hline Age (years) & $49.6 \pm 10.9$ & $50.0 \pm 11.2$ & $51.6 \pm 10.5^{\mathrm{a}, \mathrm{b}}$ & $50.4 \pm 10.9$ & $<0.001$ \\
\hline FT4 $(\mathrm{mg} / \mathrm{dL})^{*}$ & $1.33 \pm 0.22$ & $1.28 \pm 0.22^{\mathrm{a}}$ & $1.33 \pm 0.22^{\mathrm{b}}$ & $1.27 \pm 0.22^{\mathrm{a}, \mathrm{c}}$ & $<0.001$ \\
\hline TSH $(\mathrm{mIU} / \mathrm{L})^{*}$ & $2.20 \pm 1.14$ & $2.20 \pm 1.11$ & $2.08 \pm 1.08^{\mathrm{a}}$ & $2.04 \pm 1.05^{\mathrm{a}}$ & 0.001 \\
\hline $\operatorname{BMI}\left(\mathrm{kg} / \mathrm{m}^{2}\right)$ & $22.1 \pm 1.7$ & $22.9 \pm 1.5^{\mathrm{a}}$ & $26.8 \pm 1.7^{\mathrm{a}, \mathrm{b}}$ & $28.6 \pm 3.5^{\mathrm{a}, \mathrm{b}, \mathrm{c}}$ & $<0.001$ \\
\hline $\mathrm{WC}(\mathrm{cm})$ & $81.0 \pm 5.8$ & $83.5 \pm 5.7^{\mathrm{a}}$ & $92.0 \pm 6.1^{\mathrm{a}, \mathrm{b}}$ & $97.0 \pm 9.3^{\mathrm{a}, \mathrm{b}, \mathrm{c}}$ & $<0.001$ \\
\hline SBP (mmHg) & $118.5 \pm 13.6$ & $123.3 \pm 14.2^{\mathrm{a}}$ & $125.2 \pm 13.2^{\mathrm{a}}$ & $128.9 \pm 13.9^{\mathrm{a}, \mathrm{b}, \mathrm{c}}$ & $<0.001$ \\
\hline $\mathrm{DBP}(\mathrm{mmHg})$ & $69.5 \pm 9.7$ & $73.0 \pm 9.9$ & $73.7 \pm 9.4^{\mathrm{a}}$ & $76.2 \pm 9.3^{\mathrm{a}, \mathrm{b}, \mathrm{c}}$ & $<0.001$ \\
\hline Heart rate (beat/min) & $63.1 \pm 9.1$ & $66.6 \pm 9.6^{\mathrm{a}}$ & $62.9 \pm 8.7^{\mathrm{b}}$ & $66.0 \pm 9.6^{\mathrm{a}, \mathrm{c}}$ & $<0.001$ \\
\hline $\mathrm{TC}(\mathrm{mg} / \mathrm{dL})$ & $201.1 \pm 33.9$ & $204.0 \pm 37.7$ & $206.6 \pm 34.3^{\mathrm{a}}$ & $209.8 \pm 37.3^{\mathrm{a}, \mathrm{b}}$ & $<0.001$ \\
\hline $\mathrm{TG}(\mathrm{mg} / \mathrm{dL})^{*}$ & $85.4 \pm 55.0$ & $129.2 \pm 85.1^{\mathrm{a}}$ & $119.6 \pm 75.9^{\mathrm{a}}$ & $155.4 \pm 93.6^{\mathrm{a}, \mathrm{b}, \mathrm{c}}$ & $<0.001$ \\
\hline HDL-C (mg/dL) & $56.4 \pm 13.0$ & $52.5 \pm 12.5^{\mathrm{a}}$ & $49.5 \pm 10.8^{\mathrm{a}, \mathrm{b}}$ & $47.0 \pm 10.2^{\mathrm{a}, \mathrm{b}, \mathrm{c}}$ & $<0.001$ \\
\hline $\mathrm{FPG}(\mathrm{mg} / \mathrm{dL})$ & $85.5 \pm 10.5$ & $95.9 \pm 10.3^{\mathrm{a}}$ & $88.1 \pm 10.1^{\mathrm{a}, \mathrm{b}}$ & $96.4 \pm 10.7^{\mathrm{a}, \mathrm{c}}$ & $<0.001$ \\
\hline FPI $(\mathrm{U} / \mathrm{L})^{*}$ & $4.8 \pm 2.1$ & $12.2 \pm 4.0^{\mathrm{a}}$ & $6.1 \pm 2.0^{\mathrm{a}, \mathrm{b}}$ & $14.9 \pm 6.9^{, \mathrm{b}, \mathrm{c}}$ & $<0.001$ \\
\hline HOMA-IR* & $1.0 \pm 0.5$ & $2.9 \pm 1.0^{\mathrm{a}}$ & $1.3 \pm 0.5^{\mathrm{a}, \mathrm{b}}$ & $3.5 \pm 1.8^{\mathrm{a}, \mathrm{b}, \mathrm{c}}$ & $<0.001$ \\
\hline $\mathrm{CRP}(\mathrm{mg} / \mathrm{dL})^{* \dagger}$ & $0.16 \pm 0.38$ & $0.20 \pm 0.58^{\mathrm{a}}$ & $0.16 \pm 0.26^{\mathrm{a}}$ & $0.25 \pm 0.52^{\mathrm{a}, \mathrm{b}, \mathrm{c}}$ & $<0.001$ \\
\hline Hypertension (\%) & $536(15.2)$ & $149(24.0)$ & $309(27.0)$ & $333(34.5)$ & $<0.001$ \\
\hline Hyperlipidemia (\%) & $781(22.1)$ & $238(40.0)$ & $432(37.7)$ & $503(52.1)$ & $<0.001$ \\
\hline Current smoker $(\%)^{\ddagger}$ & $636(19.9)$ & $103(20.7)$ & $272(26.2)$ & $199(24.8)$ & $<0.001$ \\
\hline Regular exercise $(\%)^{\S}$ & $870(29.0)$ & $131(28.9)$ & $251(26.3)$ & $163(22.2)$ & 0.002 \\
\hline
\end{tabular}

Data are expressed as means \pm SD or number (percentage) unless otherwise indicated.

NW: normal weight; OW/OB: overweight/obese; IS: insulin sensitive; IR: insulin resistance; BMI: body mass index; WC: waist circumference; WHR: waisthip ratio; SBP: systolic blood pressure; DBP: diastolic blood pressure; TG: triglyceride; HDL-C: high-density lipoprotein cholesterol; LDL-C: low-density lipoprotein cholesterol; FPG: fasting plasma glucose; FPI: fasting plasma insulin; HOMA-IR; CRP: C-reactive protein.

One-way ANOVA and Tukey's post-hoc for continuous variables. ${ }^{a} P<0.05$ versus NW-IS; ${ }^{b} P<0.05$ versus NW-IR; ${ }^{c} P<0.05$ versus OW/OB-IS; ${ }^{*}$ tested by log-transformed; ${ }^{\dagger}$ measured in 4877 subjects; ${ }^{\ddagger}$ measured in $5529 ;{ }^{\S}$ regular exercise was defined as exercise for more than 30 minutes at a time more than three times a week (measured only in 5140 subjects).

TG, FPI, CRP, and HOMA-IR, and positively with HDL$\mathrm{C}$, but no differences were observed in FPG and BP levels in both men and women. TSH levels showed a rather weak association with BMI and HOMA-IR only in women (Table 2). As shown in Figure 1, the FT4 level decreased in accordance with the increasing quartiles of HOMA-IR and higher degree of obesity in men and women (all $P<0.01$ ). However, no differences in TSH existed across HOMA-IR quartiles by obesity groups except a very week association in NW women $(P=0.046)$. In a multivariate linear regression model including obesity measures and insulin resistance together, HOMA-IR were significantly associated with FT4 levels both in men $(\beta=-0.155, P<0.001)$ women $(\beta=$ $-0.175, P<0.001$ ) (Table 3 ). On the other hand, there is no association between TSH levels and HOMA-IR in both genders. Furthermore, FT4 levels were significantly associated with HOMA-IR $(\beta=-0.126, P<0.001)$ using a multivariate linear regression model adjusted for age, sex, BMI, WC, hypertension, heart rate, hyperlipidemia, and TSH (see Supplementary Table 1 in Supplementary Material available online at http://dx.doi.org/10.1155/2014/104318).

3.3. Risk for Insulin Resistance according to Serum FT4 Quartiles. The prevalence of insulin resistance increased significantly with decreasing FT4 quartiles for the total and
TABLE 2: Age-adjusted Pearson's correlation coefficients of FT4 and TSH with clinical variables.

\begin{tabular}{lcccc}
\hline & \multicolumn{2}{c}{$\mathrm{FT}^{*}$} & \multicolumn{2}{c}{ TSH$^{*}$} \\
& Men & Women & Men & Women \\
\hline Age & $-0.15^{\ddagger}$ & -0.03 & 0.03 & $0.06^{\ddagger}$ \\
BMI $\left(\mathrm{kg} / \mathrm{m}^{2}\right)$ & $-0.14^{\ddagger}$ & $-0.12^{\ddagger}$ & -0.01 & $-0.05^{\ddagger}$ \\
WC $(\mathrm{cm})$ & $-0.14^{\ddagger}$ & $-0.09^{\ddagger}$ & -0.02 & -0.03 \\
SBP $(\mathrm{mmHg})$ & -0.01 & -0.01 & 0.001 & -0.02 \\
DBP $(\mathrm{mmHg})$ & 0.002 & -0.01 & 0.03 & -0.01 \\
Heart rate $(\mathrm{beat} / \mathrm{min})$ & $0.06^{\ddagger}$ & $0.07^{\ddagger}$ & $-0.04^{\dagger}$ & $-0.06^{\ddagger}$ \\
TC $(\mathrm{mg} / \mathrm{dL})$ & $0.05^{\ddagger}$ & 0.04 & 0.02 & $0.05^{\ddagger}$ \\
TG $(\mathrm{mg} / \mathrm{dL})^{*}$ & $-0.05^{\ddagger}$ & $-0.14^{\ddagger}$ & $0.08^{\ddagger}$ & $0.04^{\dagger}$ \\
HDL-C $(\mathrm{mg} / \mathrm{dL})$ & $0.09^{\ddagger}$ & $0.09^{\ddagger}$ & -0.03 & -0.003 \\
FPG $(\mathrm{mg} / \mathrm{dL})$ & $-0.04^{\dagger}$ & -0.02 & 0.03 & 0.02 \\
FPI $(\mathrm{U} / \mathrm{L})^{*}$ & $-0.18^{\ddagger}$ & $-0.17^{\ddagger}$ & 0.01 & $-0.07^{\ddagger}$ \\
HOMA-IR & $-0.17^{\ddagger}$ & $-0.16^{\ddagger}$ & 0.02 & $-0.05^{\ddagger}$ \\
hsCRP $^{*}$ & $-0.07^{\ddagger}$ & $-0.06^{\ddagger}$ & -0.03 & -0.03 \\
\hline
\end{tabular}

${ }^{*}$ Tested by log-transformed; ${ }^{\dagger} P<0.05 ;{ }^{\ddagger} P<0.01$.

each subgroup divided by obesity (Table 4). Multivariate logistic analysis was performed to investigate an independent association between FT4 levels and insulin resistance. After 
TABLE 3: Multiple regression analysis of determinants of serums FT4 and TSH concentrations.

\begin{tabular}{|c|c|c|c|c|c|c|c|c|}
\hline & \multicolumn{4}{|c|}{$\mathrm{FT}^{*}$} & \multicolumn{4}{|c|}{$\mathrm{TSH}^{*}$} \\
\hline & \multicolumn{2}{|c|}{ Men } & \multicolumn{2}{|c|}{ Women } & \multicolumn{2}{|c|}{ Men } & \multicolumn{2}{|c|}{ Women } \\
\hline & $\beta^{\mathrm{a}}$ & $P$ & $\beta$ & $P$ & $\beta$ & $P$ & $\beta$ & $P$ \\
\hline Age & -0.149 & $<0.001$ & 0.025 & 0.233 & 0.032 & 0.083 & 0.062 & 0.004 \\
\hline BMI & -0.016 & 0.644 & -0.116 & 0.002 & -0.009 & 0.803 & -0.071 & 0.059 \\
\hline WC & -0.064 & 0.063 & -0.064 & 0.091 & -0.039 & 0.267 & 0.050 & 0.189 \\
\hline Hypertension & -0.008 & 0.662 & 0.050 & 0.013 & -0.011 & 0.541 & -0.031 & 0.131 \\
\hline Heart rate & 0.087 & $<0.001$ & 0.103 & $<0.001$ & -0.050 & 0.004 & -0.046 & 0.016 \\
\hline Hyperlipidemia & 0.042 & 0.017 & 0.031 & 0.116 & 0.062 & $<0.001$ & 0.028 & 0.154 \\
\hline HOMA-IR* & -0.155 & $<0.001$ & -0.175 & $<0.001$ & 0.040 & 0.054 & -0.036 & 0.099 \\
\hline$R^{2}(\%)$ & \multicolumn{2}{|c|}{6.4} & \multicolumn{2}{|c|}{4.5} & \multicolumn{2}{|c|}{0.9} & \multicolumn{2}{|c|}{1.1} \\
\hline
\end{tabular}

${ }^{*}$ Tested by log-transformed; ${ }^{a}$ standardized coefficient. These results are adjusted for all of the other variables listed in the table.

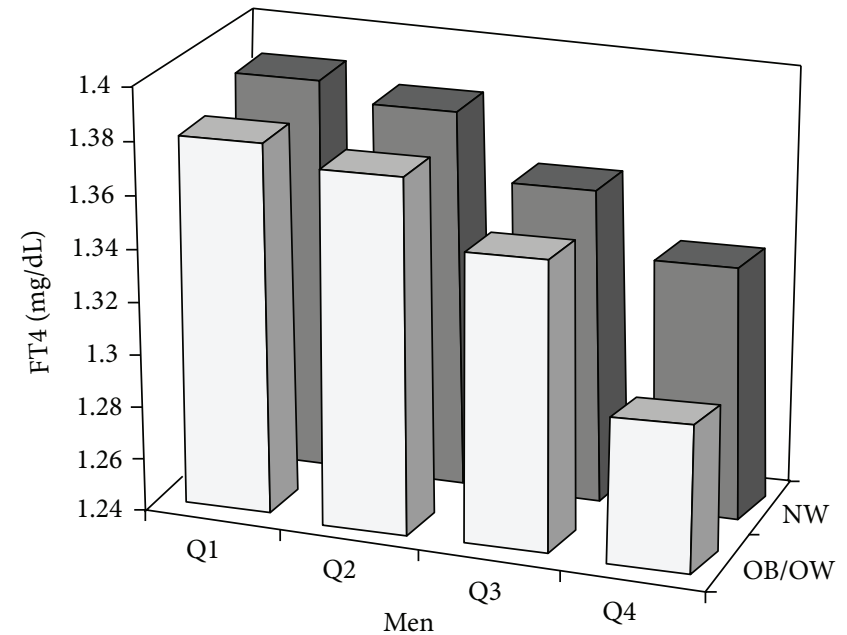

(a)

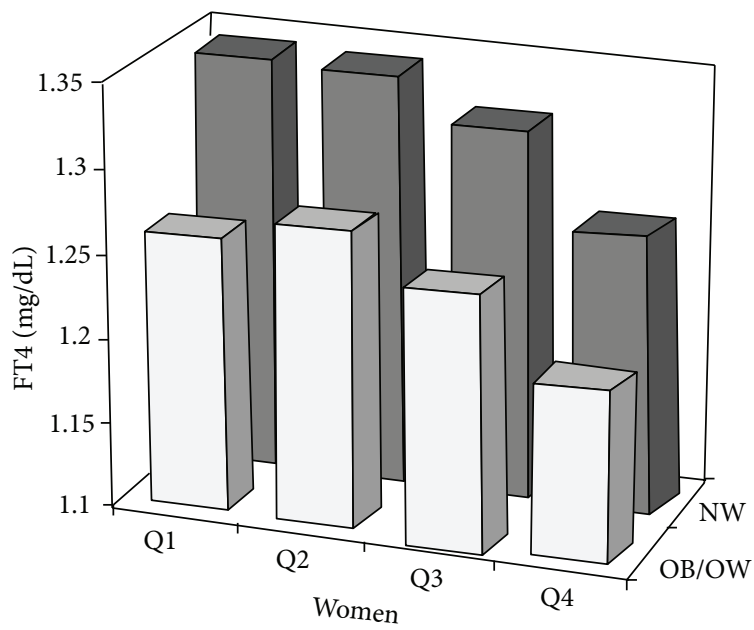

(c)

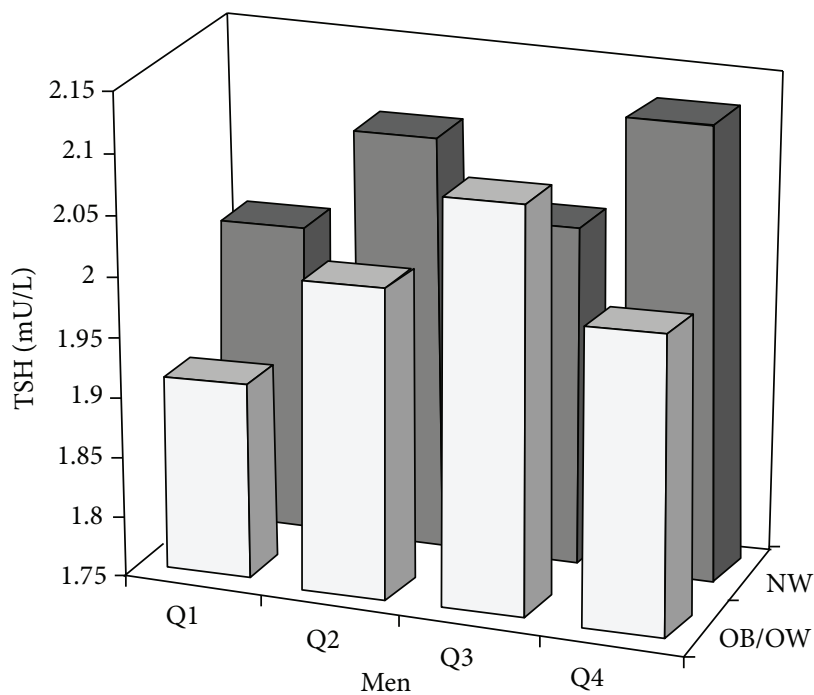

(b)

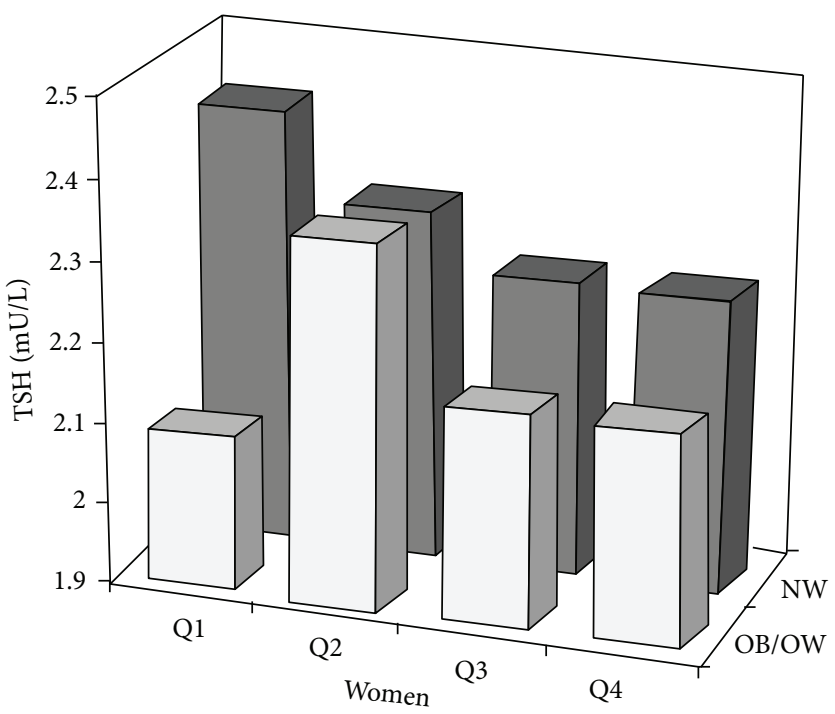

(d)

FIgURE 1: Age-adjusted relationship between HOMA-IR quartiles, obesity categories, and FT4 or TSH in men (a, b) and women (c, d). 
adjusting for age, sex, WC, heart rate, hypertension, hyperlipidemia, regular exercise, and smoking, ORs (95\% CIs) for having insulin resistance from the highest to lowest FT4 quartiles, Q4 to Q1, were 1 (Ref), 1.26 (1.01-1.57), 1.54 (1.241.93 ), and 1.99 (1.61-2.46) for the entire group ( $P$ for trend $<$ $0.001 ;$ Model 3). In the subgroup analysis, the fully adjusted ORs (95\% CIs) for the lowest versus the highest quartile were 1.76 (1.31-2.38) in NW and 2.19 (1.62-2.96) in OW/OB groups, respectively. Further adjustment for log-transformed TSH levels did not change any of the associations presented in Table 4.

\section{Discussion}

Several studies have highlighted subsets of obesity, such as metabolically healthy but obese or metabolically unhealthy but normal weighted subjects. Previous epidemiological studies have suggested that this concept could improve risk prediction of CV events, as compared to using risk assessment based on BMI alone [3]. A recent meta-analysis revealed that an unhealthy metabolic status provides an increased risk for all-cause mortality and CV events regardless of normal weight, overweight, or obesity. Those analyses stressed the importance to assess the metabolic status in addition to BMI in the evaluation of long-term outcomes [11]. However, the underlying mechanisms that provoke insulin resistance in lean subjects or protect against it in obese subjects remain unclear. Clinical studies have reported that visceral fat [11$14]$, older age, physical inactivity, and smoking $[15,16]$ are associated with the "at risk" phenotype. In addition, close relation to biochemical markers including lipid profiles [14], hepatic enzymes $[11,12,17]$, adipokines $[18,19]$, and IGF-1 [20] suggests that these factors could contribute to obesity phenotypes.

In the present study, we found that small differences in FT4 levels were closely associated with obesity, lipid profiles, and insulin resistance in euthyroid healthy subjects. In addition, lower FT4 activity within reference ranges was significantly associated with insulin resistance after adjusting for central obesity and other confounding factors. The association between low normal FT4 levels and insulin resistance remained significant even in the subgroups divided into NW and $\mathrm{OB} / \mathrm{OW}$ subjects, suggesting that thyroid activity may be involved in the development of obesity subtypes.

Thyroid hormone regulates the basal energy expenditure and influences glucose and lipid metabolism [4]. Accordingly, a number of studies have reported associations between thyroid function and obesity and obesity-related conditions such as hyperglycemia, hypertension, hyperlipidemia, and metabolic syndrome [6-10]. In the present study, we found inverse associations between FT4 levels within the reference ranges and adiposity quantified by BMI and WC, consistent with previous studies [21-23]. Several plausible mechanisms have been postulated. One explanation is that reduced thyroid function causes obesity through a lower basal metabolic rate, in line with the mechanisms suggested in hypothyroidism [4]. This is further supported by another study, which found that slightly decreased thyroid function within the normal range was correlated with weight gain during a 5-year follow-up in 4082 subjects [24]. Another explanation is that thyroid hormone levels could be altered as a consequence of obesity. Several studies have suggested a role for obesity in the development of thyroid insufficiency in the tissue based on reduced expression of T3 and TSH receptors in the fat of obese subjects [25]. Other researchers have interpreted the frequent observation of isolated TSH elevation in obesity as a mere manifestation rather than functional defect, resulting from deranged hypothalamic-pituitary axis or effects of increased leptin on TRH production and type 2 iodothyronine deiodinase (D2) inhibition in the thyrotrophs [26]. As obese individuals frequently show high insulin resistance, discerning an independent association between insulin resistance, obesity, and thyroid function is difficult. A few studies have investigated the associations between thyroid function and insulin resistance considering the impact of obesity in euthyroid ranges, showing significant relationships with mild thyroid dysfunction [10, 27, 28], although this is controversial $[22,29,30]$. Notably, the current study identified a clear association between thyroid hormone levels and HOMA-IR, independent of adiposity, which remained statistically significant after adjustment for obesity measures or by subgroup analysis including NW subjects, free from any confounding effect of obesity. This finding is important due to the growing evidence indicating that a slight change in thyroid function in euthyroid subjects is significantly associated with atherosclerotic vascular changes (as shown in our previous data) [31]. Therefore, thyroid function may play a role in the pathogenesis of atherosclerosis via increased insulin resistance even in euthyroid ranges. However, higher insulin resistance has been reported in both hyperthyroidism and hypothyroidism, as compared to euthyroidism [32]. These contrasting findings may be explained by the divergent effects of thyroid hormone on different tissues. In hyperthyroidism, thyroid hormone can antagonize insulin action on the liver leading to increased hepatic glucose output by the sympathetic pathway from the hypothalamus and transcriptional regulation of metabolic genes [32]. Conversely, peripheral insulin resistance in muscle and adipose tissue could develop via a link to low leptin levels, reduced muscle oxidative capacity, impaired GLUT4 expression, and diminished blood flow in hypothyroidism [33, 34]. Although the physiological mechanism could not be determined in the current study, the graded association between FT4 levels and insulin sensitivity in euthyroid subjects postulates the possible influence of low FT4 levels on insulin resistance by mechanisms related to hypothyroidism to a lesser degree. Additionally, hyperinsulinemia could promote thyroid insufficiency through increased D2 activity in the thyrotrophs [35]. However, compared to somewhat weak and undetermined biological relationships, in the present study we found strong associations between FT4 levels and HOMA-IR, independent of central adiposity. Thus, as suggested by previous studies, this association might be explained by an indirect link via shared genetic [36] or environmental factors [37] influencing both thyroid function and insulin resistance in euthyroid subjects rather than a directly linked casual relation. For example, insulin resistance has been reported in subjects with 
TABLE 4: Adjusted odd ratios (ORs) and 95\% confidence intervals (CIs) for insulin resistance according to FT4 quartiles.

\begin{tabular}{|c|c|c|c|c|c|}
\hline & \multicolumn{5}{|c|}{ Quartile of FT4 levels (mg/dL) } \\
\hline & Q1 & Q2 & Q3 & Q4 & $P$ for trend \\
\hline \multicolumn{6}{|l|}{ Total } \\
\hline$N$ & 1602 & 1458 & 1626 & 1555 & \\
\hline Model 1 & $2.17(1.84-2.57)$ & $1.62(1.37-1.93)$ & $1.33(1.12-1.58)$ & 1 (Ref) & $<0.001$ \\
\hline Model 2 & $1.99(1.65-2.40)$ & $1.54(1.27-1.87)$ & $1.21(1.00-1.47)$ & 1 (Ref) & $<0.001$ \\
\hline Model 3 & $1.99(1.61-2.46)$ & $1.54(1.24-1.93)$ & $1.26(1.01-1.57)$ & 1 (Ref) & $<0.001$ \\
\hline \multicolumn{6}{|l|}{ NW } \\
\hline$N$ & 970 & 945 & 1110 & 1106 & \\
\hline Model 1 & $1.76(1.37-2.26)$ & $1.46(1.13-1.89)$ & $1.30(1.01-1.68)$ & 1 (Ref) & 0.001 \\
\hline Model 2 & $1.85(1.43-2.40)$ & $1.48(1.13-1.94)$ & $1.21(0.93-1.57)$ & 1 (Ref) & $<0.001$ \\
\hline Model 3 & $1.76(1.31-2.38)$ & $1.48(1.08-2.02)$ & $1.27(0.94-1.73)$ & 1 (Ref) & 0.002 \\
\hline \multicolumn{6}{|l|}{ OW/OB } \\
\hline$N$ & 632 & 513 & 516 & 449 & \\
\hline Model 1 & $2.23(1.74-2.87)$ & $1.60(1.24-2.08)$ & $1.30(1.00-1.69)$ & 1 (Ref) & $<0.001$ \\
\hline Model 2 & $2.13(1.62-2.79)$ & $1.60(1.21-2.12)$ & $1.21(0.92-1.61)$ & 1 (Ref) & $<0.001$ \\
\hline Model 3 & $2.19(1.62-2.96)$ & $1.60(1.17-2.20)$ & $1.23(0.90-1.68)$ & 1 (Ref) & $<0.001$ \\
\hline
\end{tabular}

Model 1: adjusted for age and sex.

Model 2: adjusted for age, sex, BMI, WC, heart rate, hypertension, and hyperlipidemia.

Model 3: adjusted for age, sex, BMI, WC, heart rate, hypertension, hyperlipidemia, regular exercise, and smoking (total, $n=4885$; NW, $n=3265$; OW/OB, $n=1620)$.

D2 Thr92Ala [38] and D2 knockout mice regardless of weight gain [39].

Interestingly, the current study demonstrates that lower FT4 levels, rather than higher TSH levels, are associated with insulin resistance. Our data is consistent with other studies that found significant association between FT4, but not TSH, with various clinical outcomes such as metabolic syndrome [10], hepatic steatosis [40], bone mass density [41], frailty [42], and atrial fibrillation [43]. We could not explain why such divergent associations exist between thyroid markers and clinical outcomes, but serum FT4 could be a more reliable marker of tissue thyroid status as previous studies suggest [10, 42, 43]. Although hypothalamic-pituitary-thyroid (HPT) axis has a key role in thyroid hormone homeostasis, peripheral thyroid activity ultimately depends on circulating T4 levels and local regulatory mechanisms of thyroid hormone that involve intracellular transportation, deiondination of T4 into active T3, and binding to nuclear receptors [44]. TSH has been considered as a highly sensitive measure of the thyroid dysfunction, but current issues challenge inverse log TSHFT4 relationship and demonstrate complex nature of the TSH response to changes in FT4 [45]. In addition, populationbased studies of euthyroid subjects have reported wide variations of FT4/TSH between individuals in contrast to narrow intraindividual variation of TSH, suggesting individual setpoint of the HPT axis, inherited as a genetic trait [46].

Our study gives clinical implications as the detection of low normal FT4 levels could indicate metabolically unhealthy subjects with combined risk factors who can benefit from early screening and medical intervention of combined risk factors. Further fundamental studies could confirm whether changed thyroid activity has a protective role in obese subjects against insulin resistance or low normal activity promotes it in nonobese euthyroid subjects.
There are several limitations in the present study. First, the cross-sectional study design limit confers causal influence of the relative thyroxine deficit on insulin resistance. Second, as this study included FT4 and TSH concentrations for thyroid function screening in a general population voluntarily receiving a health exam, the total $\mathrm{T} 4$ and total or free $\mathrm{T} 3 \mathrm{l}$ levels were unavailable. As moderately elevated T3 levels are commonly observed in obese subjects [26], inverse associations between FT4 and obesity parameters in the present study possibly arose from increased free T3/FT4 ratio, a surrogate of high deiodinase activity (which converts T4 to T3). However, contradictory data exist on the metabolic impact of the free T3/FT4 rato. An experimental study observed that mice with a disrupted Dio2 gene (D2KO) were susceptible to diet-induced obesity and insulin-resistance independent of obesity [39] and suggested involvement of D2 activity in the development of metabolic abnormalities. Measurement of T3 levels could help in the understanding of thyroid hormone physiology by determining the association between the free T3/FT4 ratio and obesity and insulin resistance. Third, we did not measure insulin resistance using the standard method; however, HOMA-IR has been used as a tool for measuring insulin resistance in a large-scale community-based study and was well correlated with insulin resistance as measured by the hyperinsulinemic clamp method [47]. Lastly, thyroid autoimmunity was not measured, which may have provided further insights. The strengths of our study include the large healthy population surveyed and the careful measures taken to minimize confounding variables.

In conclusion, low normal FT4 levels were independently related to "metabolically unhealthy" in NW and OW/OB euthyroid subjects. Further studies are needed to investigate the mechanisms by which low FT4 levels are linked to high insulin resistance in euthyroid ranges. 


\section{Conflict of Interests}

The authors have no potential conflict of interests associated with this research.

\section{Authors' Contribution}

Jeong Ah Shin and Eun young Mo contributed equally to this project as cofirst authors. Eun Sook Kim conceived of the study, participated in its design, and wrote the paper. Jeong Ah Shin and Eun Young Mo participated in its design and reviewed and wrote the paper. Sung Dae Moon and Je Ho Han reviewed and edited the paper. All authors read and approved the final version of the paper.

\section{Acknowledgments}

The authors would like to give special thanks to Dr. Juyoung Shin (Health Promotion Center, Seoul St. Mary's hospital and The Catholic University of Korea, College of Medicine, Seoul, Republic of Korea) for providing insightful comments and suggestions.

\section{References}

[1] R. Andres, "Effect of obesity on total mortality," International Journal of Obesity, vol. 4, no. 4, pp. 381-386, 1980.

[2] N. B. Ruderman, S. H. Schneider, and P. Berchtold, "The "metabolically-obese," normal-weight individual," American Journal of Clinical Nutrition, vol. 34, no. 8, pp. 1617-1621, 1981.

[3] J. Ärnlöv, E. Ingelsson, J. Sundström, and L. Lind, "Impact of body mass index and the metabolic syndrome on the risk of cardiovascular disease and death in middle-aged men," Circulation, vol. 121, no. 2, pp. 230-236, 2010.

[4] J. E. Silva, "The thermogenic effect of thyroid hormone and its clinical implications," Annals of Internal Medicine, vol. 139, no. 3, pp. 205-213, 2003.

[5] N. Rodondi, W. P. J. Den Elzen, D. C. Bauer et al., "Subclinical hypothyroidism and the risk of coronary heart disease and mortality," Journal of the American Medical Association, vol. 304, no. 12, pp. 1365-1374, 2010.

[6] S. Ruhla, M. O. Weickert, A. M. Arafat et al., "A high normal TSH is associated with the metabolic syndrome," Clinical Endocrinology, vol. 72, no. 5, pp. 696-701, 2010.

[7] S. M. Boekholdt, S. M. Titan, W. M. Wiersinga et al., "Initial thyroid status and cardiovascular risk factors: the EPIC-Norfolk prospective population study," Clinical Endocrinology, vol. 72, no. 3, pp. 404-410, 2010.

[8] H. T. Park, G. J. Cho, K. H. Ahn et al., "Thyroid stimulating hormone is associated with metabolic syndrome in euthyroid postmenopausal women," Maturitas, vol. 62, no. 3, pp. 301-305, 2009.

[9] S.-Y. Lin, Y.-Y. Wang, P.-H. Liu, W.-A. Lai, and W. H.-H. Sheu, "Lower serum free thyroxine levels are associated with metabolic syndrome in a Chinese population," Metabolism: Clinical and Experimental, vol. 54, no. 11, pp. 1524-1528, 2005.

[10] A. Roos, S. J. L. Bakker, T. P. Links, R. O. B. Gans, and B. H. R. Wolffenbuttel, "Thyroid function is associated with components of the metabolic syndrome in euthyroid subjects," Journal of Clinical Endocrinology and Metabolism, vol. 92, no. 2, pp. 491496, 2007.
[11] M. Brochu, A. Tchernof, I. J. Dionne et al., "What are the physical characteristics associated with a normal metabolic profile despite a high level of obesity in postmenopausal women?" Journal of Clinical Endocrinology and Metabolism, vol. 86, no. 3, pp. 1020-1025, 2001.

[12] A. D. Karelis, M. Faraj, J.-P. Bastard et al., "The metabolically healthy but obese individual presents a favorable inflammation profile," Journal of Clinical Endocrinology and Metabolism, vol. 90, no. 7, pp. 4145-4150, 2005.

[13] R. Weiss, S. E. Taksali, S. Dufour et al., "The "Obese insulinsensitive" adolescent: importance of adiponectin and lipid partitioning," Journal of Clinical Endocrinology and Metabolism, vol. 90, no. 6, pp. 3731-3737, 2005.

[14] M.-J. Shin, Y. J. Hyun, O. Y. Kim, J. Y. Kim, Y. Jang, and J. H. Lee, "Weight loss effect on inflammation and LDL oxidation in metabolically healthy but obese (MHO) individuals: low inflammation and LDL oxidation in MHO women," International Journal of Obesity, vol. 30, no. 10, pp. 1529-1534, 2006.

[15] R. P. Wildman, P. Muntner, K. Reynolds et al., "The obese without cardiometabolic risk factor clustering and the normal weight with cardiometabolic risk factor clustering: prevalence and correlates of 2 phenotypes among the US population (NHANES 1999-2004)," Archives of Internal Medicine, vol. 168, no. 15, pp. 1617-1624, 2008.

[16] C. L. Jennings, E. V. Lambert, M. Collins, Y. Joffe, N. S. Levitt, and J. H. Goedecke, "Determinants of insulin-resistant phenotypes in normal-weight and obese black african women," Obesity, vol. 16, no. 7, pp. 1602-1609, 2008.

[17] E. Succurro, M. A. Marini, S. Frontoni et al., "Insulin secretion in metabolically obese, but normal weight, and in metabolically healthy but obese individuals," Obesity, vol. 16, no. 8, pp. 18811886, 2008.

[18] C. A. Aguilar-Salinas, E. G. García, L. Robles et al., "High adiponectin concentrations are associated with the metabolically healthy obese phenotype," Journal of Clinical Endocrinology and Metabolism, vol. 93, no. 10, pp. 4075-4079, 2008.

[19] D. H. St-Pierre, A. D. Karelis, L. Coderre et al., "Association of acylated and nonacylated ghrelin with insulin sensitivity in overweight and obese postmenopausal women," Journal of Clinical Endocrinology and Metabolism, vol. 92, no. 1, pp. 264269, 2007.

[20] M. A. Marini, E. Succurro, S. Frontoni et al., "Metabolically healthy but obese women have an intermediate cardiovascular risk profile between healthy nonobese women and obese insulin-resistant women," Diabetes Care, vol. 30, no. 8, pp. 21452147, 2007.

[21] B. Ambrosi, B. Masserini, L. Iorio et al., "Relationship of thyroid function with body mass index and insulin-resistance in euthyroid obese subjects," Journal of Endocrinological Investigation, vol. 33, no. 9, pp. 640-643, 2010.

[22] G. de Pergola, A. Ciampolillo, S. Paolotti, P. Trerotoli, and R. Giorgino, "Free triiodothyronine and thyroid stimulating hormone are directly associated with waist circumference, independently of insulin resistance, metabolic parameters and blood pressure in overweight and obese women," Clinical Endocrinology, vol. 67, no. 2, pp. 265-269, 2007.

[23] A. E. Makepeace, A. P. Bremner, P. O’Leary et al., "Significant inverse relationship between serum free $\mathrm{T} 4$ concentration and body mass index in euthyroid subjects: differences between smokers and nonsmokers," Clinical Endocrinology, vol. 69, no. 4, pp. 648-652, 2008. 
[24] N. Knudsen, P. Laurberg, L. B. Rasmussen et al., "Small differences in thyroid function may be important for body mass index and the occurrence of obesity in the population," Journal of Clinical Endocrinology and Metabolism, vol. 90, no. 7, pp. 4019-4024, 2005.

[25] M. Nannipieri, F. Cecchetti, M. Anselmino et al., "Expression of thyrotropin and thyroid hormone receptors in adipose tissue of patients with morbid obesity and/or type 2 diabetes: effects of weight loss," International Journal of Obesity, vol. 33, no. 9, pp. 1001-1006, 2009.

[26] T. Reinehr, "Obesity and thyroid function," Molecular and Cellular Endocrinology, vol. 316, no. 2, pp. 165-171, 2010.

[27] A. Mueller, C. Schöfl, R. Dittrich et al., "Thyroid-stimulating hormone is associated with insulin resistance independently of body mass index and age in women with polycystic ovary syndrome," Human Reproduction, vol. 24, no. 11, pp. 2924-2930, 2009.

[28] J. D. J. Garduño-Garcia, U. Alvirde-Garcia, G. López-Carrasco et al., "TSH and free thyroxine concentrations are associated with differing metabolic markers in euthyroid subjects," European Journal of Endocrinology, vol. 163, no. 2, pp. 273-278, 2010.

[29] G. Muscogiuri, G. Sorice, T. Mezza et al., "High-normal TSH values in obesity: is it insulin resistance or adipose tissue's guilt?" Obesity, vol. 21, pp. 101-106, 2012.

[30] G. Roef, B. Lapauw, S. Goemaere et al., "Body composition and metabolic parameters are associated with variation in thyroid hormone levels among euthyroid young men," European Journal of Endocrinology, vol. 167, pp. 719-726, 2012.

[31] E. S. Kim, J. Y. Shin, D. J. Lim et al., "Association between low serum free thyroxine concentrations and coronary artery calcification in healthy euthyroid subjects," Thyroid, vol. 22, pp. 870-876, 2012.

[32] G. Brenta, "Why can insulin resistance be a natural consequence of thyroid dysfunction?” Journal of Thyroid Research, vol. 2011, Article ID 152850, 9 pages, 2011.

[33] P. Cettour-Rose, C. Theander-Carrillo, C. Asensio et al., "Hypothyroidism in rats decreases peripheral glucose utilisation, a defect partially corrected by central leptin infusion," Diabetologia, vol. 48, no. 4, pp. 624-633, 2005.

[34] M. Peppa, C. Koliaki, P. Nikolopoulos, and S. A. Raptis, "Skeletal muscle insulin resistance in endocrine disease," Journal of Biomedicine and Biotechnology, vol. 2010, Article ID 527850, 13 pages, 2010.

[35] L. A. Gavin, M. Moller, F. McMahon, R. Gulli, and R. R. Cavalieri, "Carbohydrate reactivation of thyroxine $5^{\prime}$-deiodinase (type II) in cultured mouse neuroblastoma cells is dependent upon new protein synthesis," Endocrinology, vol. 124, no. 2, pp. 635-641, 1989.

[36] J. Després, "What is "metabolically healthy obesity"?: from epidemiology to pathophysiological insights," Journal of Clinical Endocrinology and Metabolism, vol. 97, pp. 2283-2285, 2012.

[37] B. O. Asvold, T. Bjøro, T. I. Nilsen, and L. J. Vatten, "Tobacco smoking and thyroid function: a population-based study," Archives of Internal Medicine, vol. 167, no. 13, pp. 1428-1432, 2007.

[38] L. H. Canani, C. Capp, J. M. Dora et al., “The type 2 deiodinase A/G (Thr92Ala) polymorphism is associated with decreased enzyme velocity and increased insulin resistance in patients with type 2 diabetes mellitus," Journal of Clinical Endocrinology and Metabolism, vol. 90, no. 6, pp. 3472-3478, 2005.

[39] A. Marsili, C. Aguayo-Mazzucato, T. Chen et al., "Mice with a targeted deletion of the type 2 deiodinase are insulin resistant and susceptible to diet induced obesity," PLOS ONE, vol. 6, no. 6, Article ID e20832, 2011.

[40] T. Ittermann, R. Haring, H. Wallaschofski et al., "Inverse association between serum free thyroxine levels and hepatic steatosis: results from the Study of Health in Pomerania," Thyroid, vol. 22, no. 6, pp. 568-574, 2012.

[41] E. Murphy, C. C. Glüer, D. M. Reid et al., "Thyroid function within the upper normal range is associated with reduced bone mineral density and an increased risk of nonvertebral fractures in healthy euthyroid postmenopausal women," Journal of Clinical Endocrinology and Metabolism, vol. 95, no. 7, pp. 3173-3181, 2010.

[42] B. B. Yeap, H. Alfonso, S. A. P. Chubb et al., "Higher free thyroxine levels are associated with frailty in older men: the Health in Men study," Clinical Endocrinology, vol. 76, no. 5, pp. 741-748, 2012.

[43] M. D. Gammage, J. V. Parle, R. L. Holder et al., "Association between serum free thyroxine concentration and atrial fibrillation," Archives of Internal Medicine, vol. 167, no. 9, pp. 928-934, 2007.

[44] G. Brent, "Mechanisms of thyroid hormone action," The Journal of Clinical Investigation, vol. 122, no. 9, pp. 3035-3043, 2012.

[45] R. Hoermann, W. Eckl, C. Hoermann, and R. Larisch, "Complex relationship between free thyroxine and TSH in the regulation of thyroid function," European Journal of Endocrinology, vol. 162, no. 6, pp. 1123-1129, 2010.

[46] R. Hoermann, J. E. M. Midgley, R. Larisch, and J. Dietrich, "Is pituitary TSH an adequate measure of thyroid hormonecontrolled homoeostasis during thyroxine treatment?" European Journal of Endocrinology, vol. 168, pp. 271-280, 2013.

[47] D. R. Matthews, J. P. Hosker, and A. S. Rudenski, "Homeostasis model assessment: Insulin resistance and $\beta$-cell function from fasting plasma glucose and insulin concentrations in man," Diabetologia, vol. 28, no. 7, pp. 412-419, 1985. 


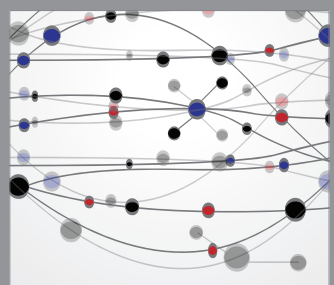

The Scientific World Journal
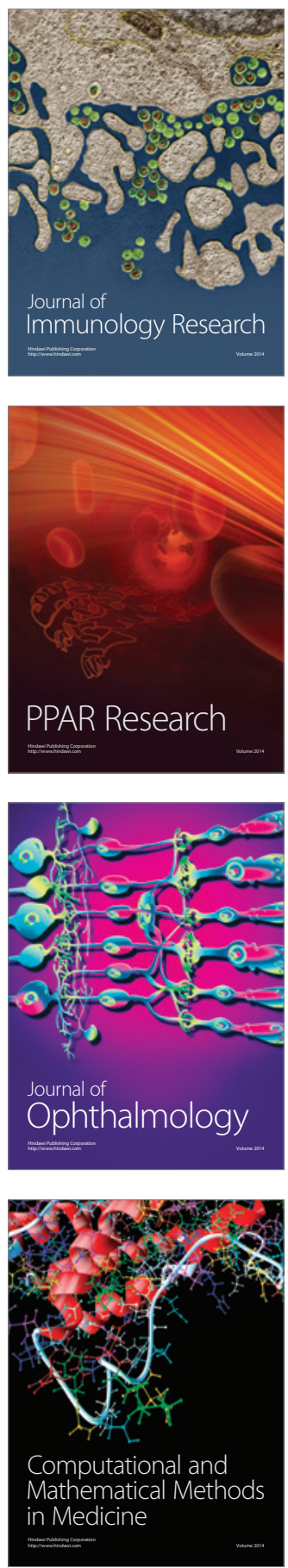

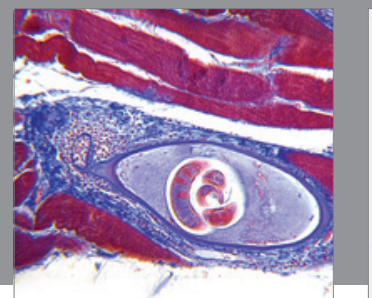

Gastroenterology

Research and Practice
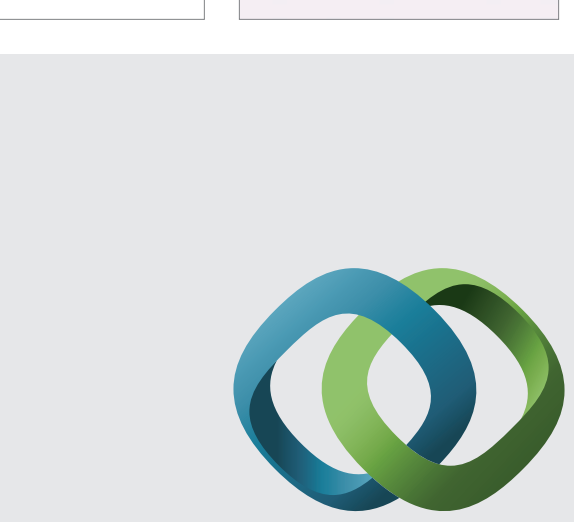

\section{Hindawi}

Submit your manuscripts at

http://www.hindawi.com
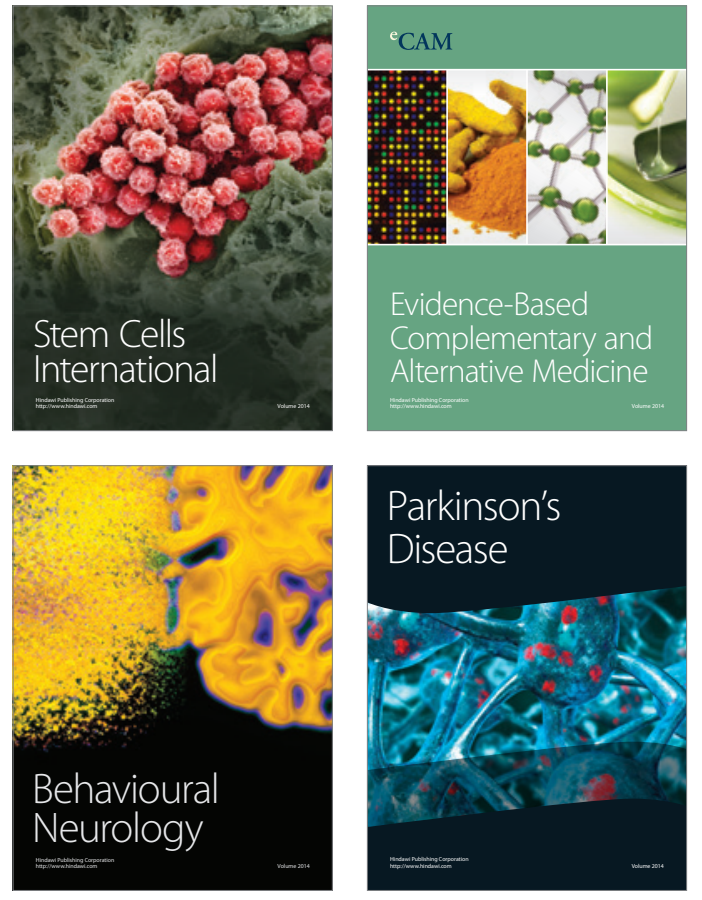
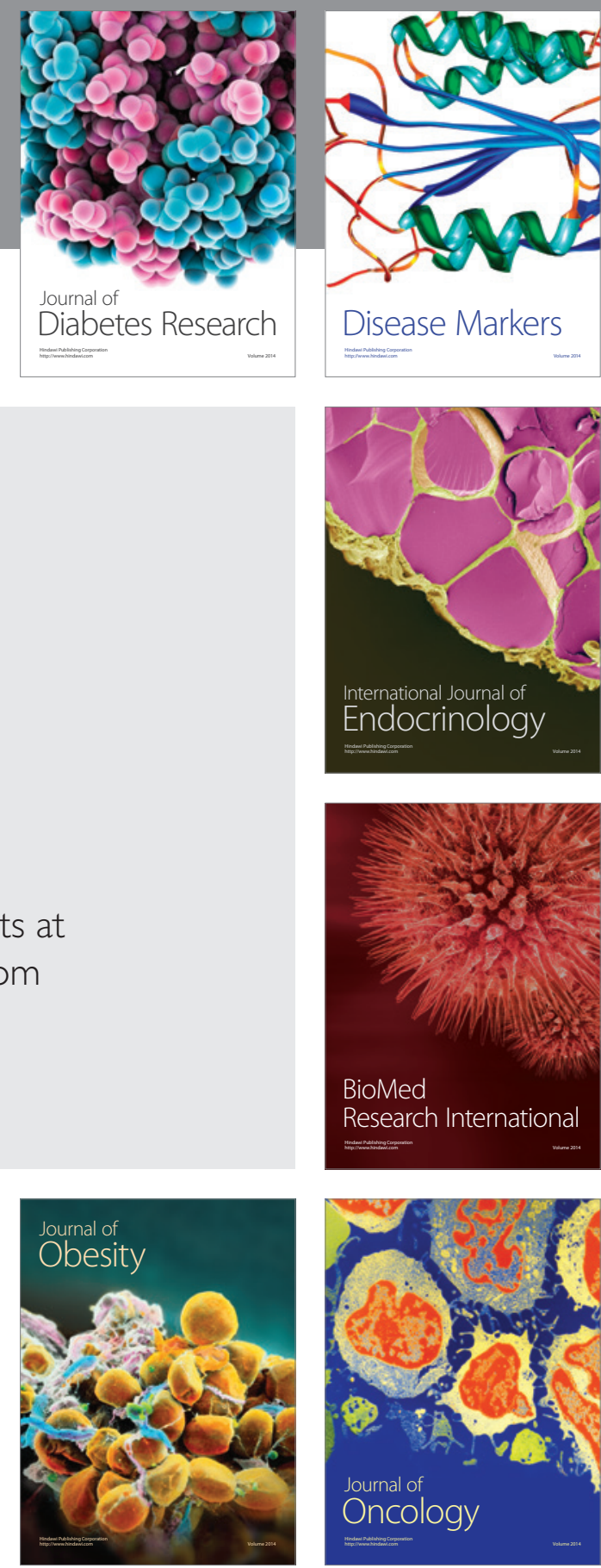

Disease Markers
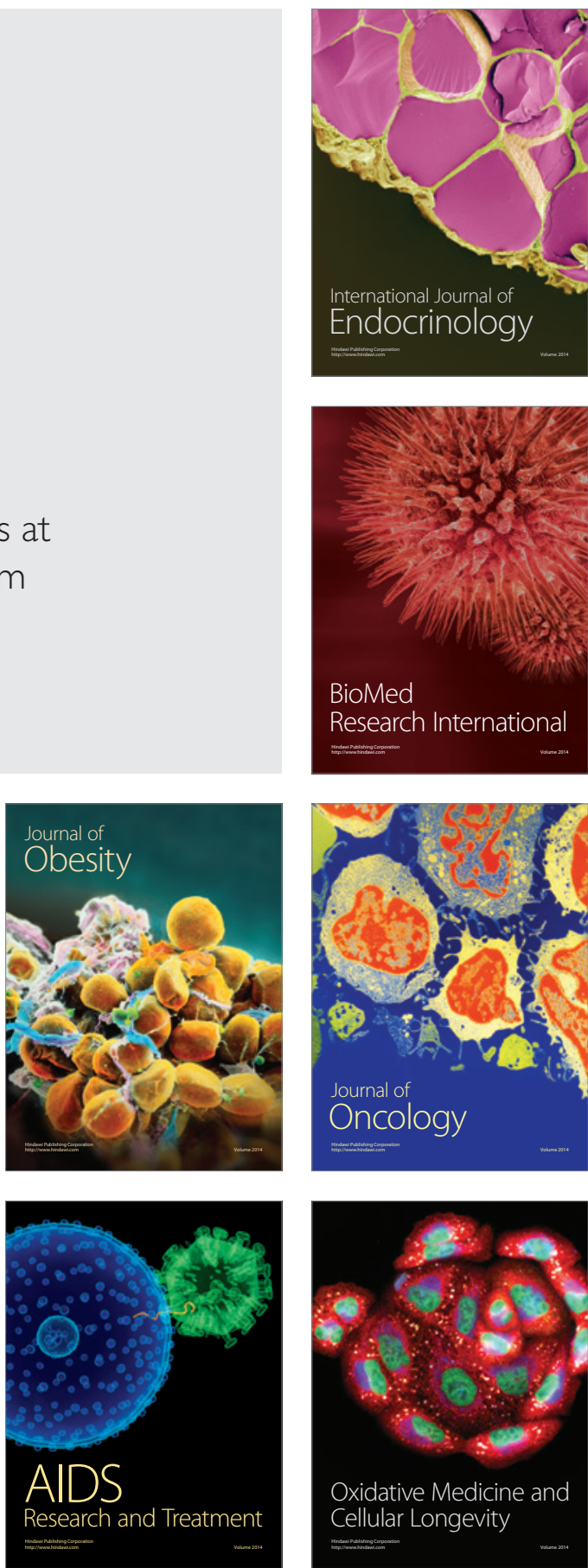